Supporting Information

\title{
Synthesis of Open-Ended, Cylindrical Au-Ag Alloy Nanostructures on a $\mathrm{Si} / \mathrm{SiO}_{\mathrm{X}}$ Surface
}

\author{
Hua Zhang, Rongchao Jin and Chad A. Mirkin* \\ Department of Chemistry and Institute for Nanotechnology, Northwestern University, \\ 2145 Sheridan Road, Evanston, IL 60208
}

\section{Experimental Section}

In a typical experiment, silicon substrates $\left(1 \times 1 \mathrm{~cm}^{2}\right.$ wafer, surface oxide thickness $\sim 500 \mathrm{~nm}$ ) were sonicated in acetone for $10 \mathrm{~min}$, rinsed with Milli-Q water (resistance > 18.1 MOhm.cm, all the reference to water below is the same), immersed into a boiling solution of ammonium hydroxide and hydrogen peroxide (volume ratio $\mathrm{NH}_{4} \mathrm{OH}: \mathrm{H}_{2} \mathrm{O}_{2}: \mathrm{H}_{2} \mathrm{O}=1: 1: 5$ ) for $1 \mathrm{~h}$, and then finally rinsed with water before drying under a $\mathrm{N}_{2}$ flow. The substrates were then transferred to a thermal evaporator chamber (vacuum pressure $<1 \times 10^{-7}$ mbar) where they were coated with a $1 \mathrm{~nm}$ Ti adhesion layer followed by $45 \mathrm{~nm}$ of Ag. AFM images of the Ag-coated substrates show that the Ag film is non-uniform and consists of large Ag grains (40-140 nm, Figure S1).

The as-prepared $\mathrm{Ag}$ substrates were immediately used for Dip-Pen Nanothography (DPN) and micro-contact printing $(\mu \mathrm{CP})$ experiments. $\mathrm{A} \mathrm{Si}_{3} \mathrm{~N}_{4}$ cantilever $(\mathrm{k}=0.05 \mathrm{~N} / \mathrm{m}$, TM Microscopes, Sunnyvale, CA) was coated with 16mercaptohexadecanoic acid (MHA) by immersing the tip into a saturated MHA solution in acetonitrile for $\sim 20 \mathrm{~s}$ followed by drying with compressed difluoroethane (Dust-off, Ted Pella, Inc.). The MHA-coated tip was used to generate a nanodot array on a Ag substrate under ambient conditions (tip-substrate holding time $3 \mathrm{~s}$, set point $=0.5 \mathrm{nN}, 22$ - $24{ }^{\circ} \mathrm{C}, 30$ - $36 \%$ relative humidity) by using an AutoProbe CP AFM (TM Microscopes, Sunnyvale, CA) and commercial lithography software (DPNWriteTM, DPN System-1, NanoInk Inc., Chicago, IL).

In a typical $\mu \mathrm{CP}$ experiment, an ethanolic MHA solution $(10 \mathrm{mM})$ was dropped onto a PDMS stamp, which consisted of a dot array $(3.5 \mu \mathrm{m}$ diameter dots $)$ with a $10 \mu \mathrm{m}$ interfeature distance. The stamp was dried under an $\mathrm{N}_{2}$ flow, and then used to transfer MHA onto the freshly prepared Ag-coated substrate. The contact time was 5-10 s.

The MHA-patterned Ag substrates (by DPN and $\mu \mathrm{CP}$ ) were treated with a ferri/ferrocyanide etching solution (a 1:1:1 (v:v:v) aqueous mixture of $30 \mathrm{mM} \mathrm{Na} 2 \mathrm{~S}_{2} \mathrm{O}_{3}, 3$ $\mathrm{mM} \mathrm{K}_{3} \mathrm{Fe}(\mathrm{CN})_{6}$ and $\left.0.3 \mathrm{mM} \mathrm{K} \mathrm{K}_{4} \mathrm{Fe}(\mathrm{CN})_{6}\right)$ for $\sim 2$ min to remove the bare $\mathrm{Ag}$ regions of the substrates. After being rinsed with $\mathrm{H}_{2} \mathrm{O}$, the substrates were immersed into a $0.5 \%$ (v/v) aqueous HF solution for $10-15 \mathrm{~s}$ to remove the $1 \mathrm{~nm}$ Ti adhesion layer. Rinsing with $\mathrm{H}_{2} \mathrm{O}$ and subsequent drying with flowing $\mathrm{N}_{2}$, resulted in the etched $\mathrm{Ag}$ structures studied herein. 


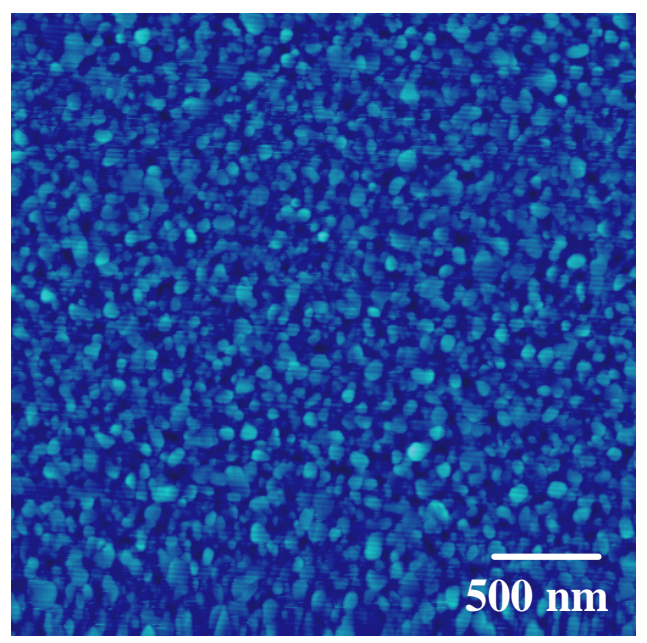

Figure S1. TM-AFM image of a $\mathrm{Si} / \mathrm{SiO}$ X $/ \mathrm{Ti} / \mathrm{Ag}$ surface showing the silver grains.
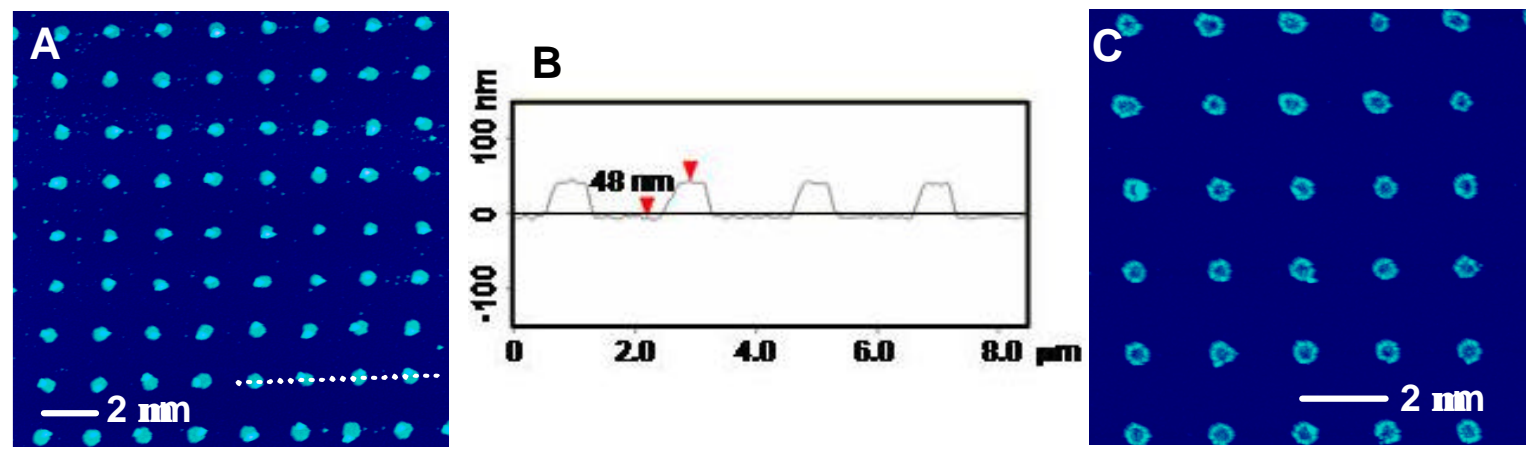

Figure S2. (A) TM-AFM image of etched Ag nanodot array. (B) The height profile was taken along the white dotted line in (A). (C) TM-AFM image of the open-ended cylindrical $\mathrm{Au}-\mathrm{Ag}$ alloy nanostructures on a $\mathrm{Si} / \mathrm{SiO}_{\mathrm{X}}$ surface.

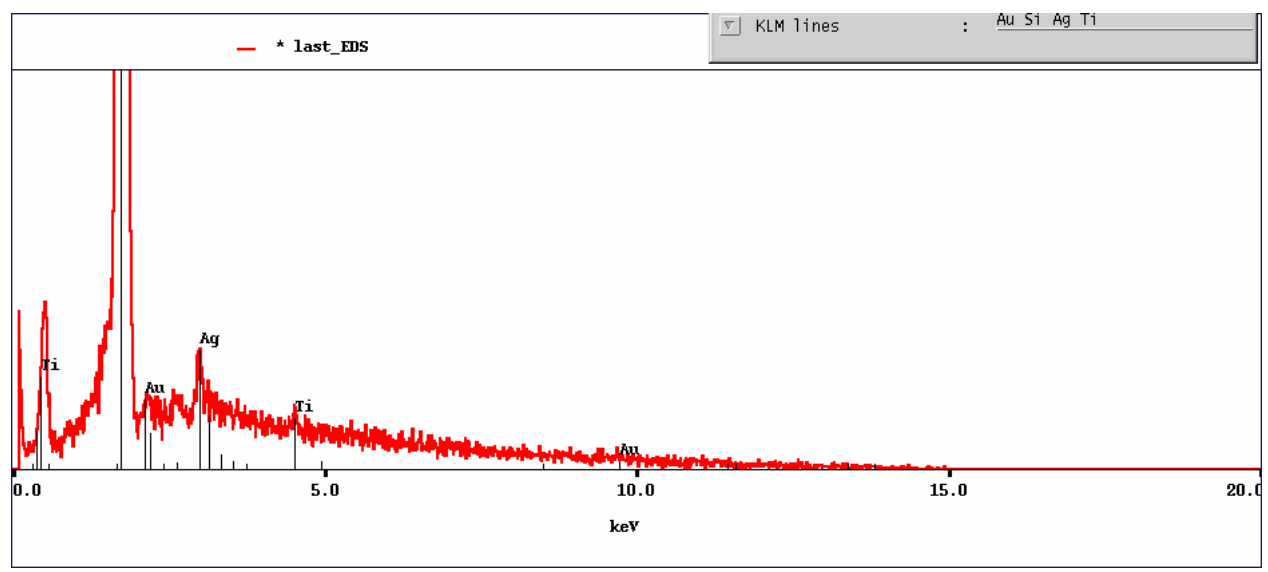

Figure S3. EDX spectroscopy of the open-ended cylindrical Au-Ag alloy nanostructures on a $\mathrm{Si} / \mathrm{SiO}_{\mathrm{X}}$ surface in Figure 1A-B in the main text. 

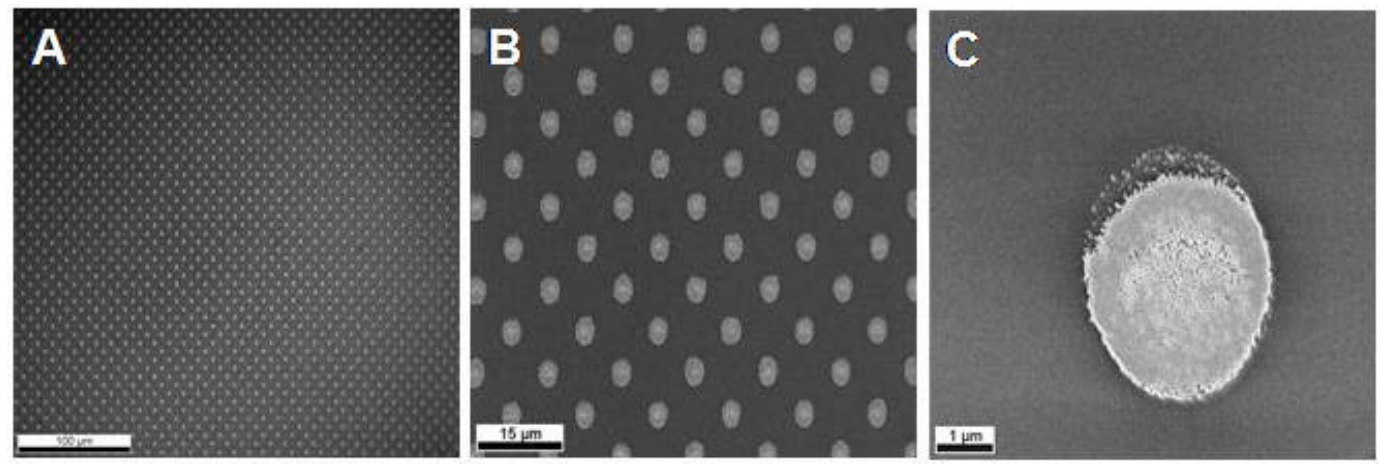

Figure S4. SEM images of an etched $\mathrm{Ag}$ microdot array on a $\mathrm{Si} / \mathrm{SiO}_{\mathrm{x}}$ surface. The MHA resist features were generated by micro-contact printing. Note the non-uniformity of the etched microstructures due to the loosely packed resist layer.

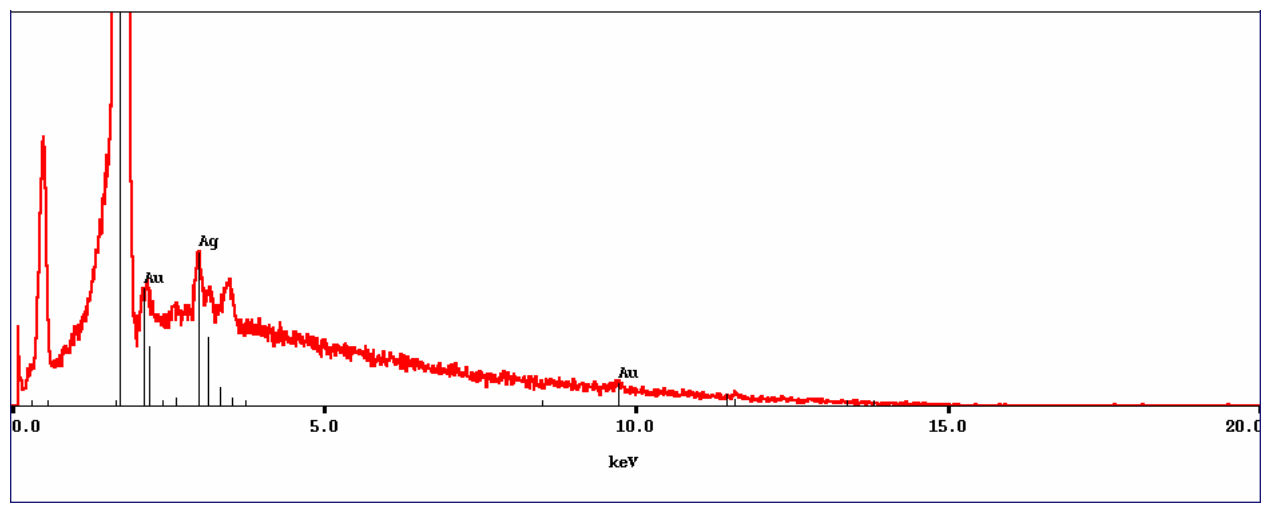

Figure S5. EDX spectroscopy of $\mathrm{Au}-\mathrm{Ag}$ cubic nanostructures in Figure 2 in the main text. 